\title{
Mulheres jornalistas em pauta: Estado da Arte sobre assédio moral e sexual no Brasil 1
}

\author{
Janaina Lopes de Amorim² \\ Thaisa Bueno ${ }^{3}$
}

\section{Resumo}

Este artigo é um Estado da Arte dos estudos relacionados ao assédio sexual e moral sofrido por mulheres jornalistas. O objetivo foi traçar um panorama das temáticas e particularidades das pesquisas sobre o assunto no Brasil nos últimos dez anos, nos programas de Mestrado e Doutorado, publicados na plataforma da Capes, bem como no evento que representa os principais estudos sobre o jornalismo, O SBPJor. Foram investigadas ainda as revistas Galáxia, Famecos e Estudos Feministas. Foram utilizadas como filtros as palavras-chaves assédio + jornalistas + mulheres. Preliminarmente o levantamento apontou para uma escassez de publicações sobre o assunto assédio no Jornalismo, embora as questões de gênero e feminismo sejam recorrentes.

Palavras-chave: Jornalismo. Estado da arte. Assédio.

\section{Women journalists on the agenda: State of the Art on moral and sexual harassment in Brazil}

\section{Abstract}

This article is a State of Art of studies related to sexual and moral harassment suffered by female journalists. The goal was draw an overview of themes and particularities of the researches into the subject in Brazil in the last ten years, in the

\footnotetext{
1 Este estudo conta com o apoio da Fapema - Fundação de Amparo à Pesquisa e ao Desenvolvimento Científico e Tecnológico do Maranhão.

2 Mestranda em Comunicação Contemporânea na UFMA de Imperatriz PPGCOM/CAPES. E-mail: jannaina.amorim@gmail.com.

3 Doutora em Comunicação pela PUC do Rio Grande do Sul. Professora e coordenadora no Programa de Mestrado em Comunicação na UFMA de Imperatriz - PPGCOM/CAPES. Email: thaisabu@gmail.com.
} 


\section{REVISTA PAUTA GERAL}

\section{ESTUDOS EM JORNALISMO}

10.5212/RevistaPautaGeral.v.6.i2.00010

master and doctorate programs, published on Capes platform, even as the events which represents the most important events about journalism, SBPJor. Were analyzed the magazines Galáxia, Famecos and Estudos Feministas. The keywords harassment + journalism + women were used as filters. Initially the research aimed a shortage of publications about harassment in journalism, although gender and feminism are recurrent.

Keywords: Journalism. State of art. Harassment.

\section{Introdução}

Este artigo se propõe a entender como o tema assédio sexual e moral envolvendo mulheres jornalistas vem sendo debatido na pesquisa brasileira na última década. O tema se justifica, entre outras razões, porque nos últimos anos as pautas feministas latinoamericanas ganharam maior visibilidade, principalmente devido ao uso das redes sociais. Entre as iniciativas que se pode destacar estão campanhas como "Chega de FiuFiu", de 2013, uma pesquisa on-line independente que trata do assédio sexual (PORTELA, 2018); e a sanção, em 2018, no Brasil, da Lei no 13.718/18 que considera a importunação sexual um crime.

Levantamento de 2018, organizado pelo Coletivo de Mulheres Jornalistas do Distrito Federal (SJPDF) apontou que $74,3 \%$ das mulheres jornalistas brasileiras já sofreram assédio sexual durante o exercício da profissão. Também naquele ano a Unesco promoveu um estudo mundial para entender e ajudar a combater o assédio on-line feito contra jornalistas mulheres. A pesquisa, posteriormente, quer organizar um manual de recomendações para orientar jornalistas a se defender de investidas tanto on-line, quanto off-line.

Estudos no interior do país repetem a realidade dos levantamentos nacionais e mundiais. Uma pesquisa que discute as diferenças de gênero nas rotinas produtivas da comunicação realizada no Maranhão, mais precisamente em Imperatriz (segunda maior cidade deste Estado), apontou que todas as jornalistas atuantes nos veículos da grande imprensa naquela cidade, em 2018, passaram por situações de assédio (MASSUCHIN; LIMA, 2019).

Assim, com o intuito de contribuir para entender o tema, este artigo buscou fazer um levantamento sobre como o assunto assédio sexual e assédio moral contra mulheres jornalistas é debatido nas pesquisas atuais no Brasil. Para isso, buscou publicações com a temática no Banco de Dados da Coordenação de Aperfeiçoamento de Pessoal de Nível 


\section{REVISTA PAUTA GERAL}

\section{ESTUDOS EM JORNALISMO}

10.5212/RevistaPautaGeral.v.6.i2.00010

Superior (Capes), na área da Comunicação e Informação, bem como nos Anais da Associação Brasileira de Pesquisadores em Jornalismo (SBJOR), evento nacional voltado para estudos em Jornalismo e de amplo reconhecimento da área. Além disso, para complementar o estudo, foram pesquisados arquivos de revistas de referência na Comunicação e Informação e que publicam estudos de jornalismo. Foram selecionadas as revistas: Galáxia, Famecos, avaliadas pela Capes (2019) como Qualis A2; e a Estudos Feministas, $\mathrm{A} 1^{4}$. Embora entendamos que existam outras revistas tão ou mais qualificadas na área no Brasil, este recorte privilegiou estas publicações no sentido de ser apresentar como um primeiro olhar para o estudo. E ainda que não contemple todas as pesquisas na área, serve como um termômetro, já que se trata de publicações de amplo reconhecimento.

Metodologicamente o estudo se enquadra no que se convencionou chamar de Estado da Arte, procedimento de caráter descritivo que permite identificar diversos aspectos de pesquisas (FERREIRA, 2002). Esse tipo de estudo é importante porque permite que, a partir dele, sejam traçados novos percursos de análise. Além disso, o tema assédio tem sido parte da rotina das mulheres jornalistas (ABRAJI, 2017; PORTELA, 2018), sendo que essa prática pode trazer danos graves para a saúde das trabalhadoras, como estresse, depressão e até mesmo suicídio (ALMEIDA, 2016). Para este artigo, foram utilizadas como filtros palavras-chaves: assédio + jornalistas + mulheres.

\section{Conceituando gênero e sua relação com o assédio no mercado de trabalho}

No final da década de 1960, os estudos teóricos voltados à mulher passam a ser evidenciados. Louro (1997) chama esse momento de "segunda onda do feminismo" - a primeira teve como marco o movimento sufragista, quando as mulheres reivindicaram o direito ao voto. Conforme a autora, neste primeiro momento as pesquisas se debruçavam em descrever as condições de vida e de trabalho das mulheres, sobretudo levantando questões relacionadas ao termo gênero.

O uso da palavra gênero, inclusive, é apontado como um dos aspectos da busca de legitimidade acadêmica em uma tentativa de reivindicar terreno. Até então, as teorias pautavam questões como a oposição binária entre feminino e masculino e a identidade

${ }^{4}$ Qualis referentes ao período de 2013 a 2016. 


\section{REVISTA PAUTA GERAL}

\section{ESTUDOS EM JORNALISMO}

10.5212/RevistaPautaGeral.v.6.i2.00010

sexual, mas não, necessariamente, tratavam de gênero enquanto sistema de relações sociais ou sexuais. Assim, os estudos se mostraram insuficientes para explicar as desigualdades entre homens e mulheres (SCOTT, 1995; BUTLER, 1993).

Para Scott (1995), o termo gênero começou a ser utilizado entre as feministas americanas para se referir às distinções baseadas no sexo e indicava a rejeição do determinismo biológico, apoiando a definição de homem e mulher em termos recíprocos ao invés do sexo sujeitado. Designava também a relação social e as construções culturais entre os sexos (BUTLER, 1993; SCOTT, 1995; LOURO 1997).

Louro (1997) enfatiza que a ideia não é negar que o gênero se constitui sobre corpos sexuados, mas reiterar que o gênero é uma construção social e histórica produzidas sobre as características biológicas, recolocando o debate para o campo social. Quando se considera essa concepção de gênero, para além do binarismo e do determinismo biológico, o pensamento passa a ser mais plural e as considerações de diversidade de representação das mulheres, e também dos homens, ficam mais visíveis (LOURO, 1997).

Baseada nessa amplitude das questões de gênero, Scott (1995) aponta a importância dos estudos que incluam abordagens focadas na educação, no sistema político, identidade subjetiva e o mercado de trabalho, que é o cerne deste estudo. De acordo com a autora, para analisar as relações sociais de gênero no mercado de trabalho é necessário, antes de tudo, levar em conta o apontamento de que o processo de hierarquização beneficia o trabalho masculino, que é mais valorizado em relação ao feminino. Outro ponto a ser salientado é a separação entre as atividades consideradas femininas e atividades consideradas masculinas (ANDRADE; ASSIS, 2018), reafirmando que a divisão sexual do trabalho estabelece uma divisão das áreas reprodutivas, ocupadas por mulheres; e as produtivas, atribuídas aos homens.

Tais fatores acabam por propiciar as violências relacionadas ao gênero, como o assédio. Tanto o assédio sexual - compreendido como ato de constranger alguém para obter vantagem ou favorecimento sexual; quanto o moral, que se trata de considerar o outro um objeto à disposição - estão relacionados ao abuso hierárquico e à dominação. Cabe ressaltar que o assédio, principalmente o sexual, é uma violência ligada ao gênero (HIGA, 2016). Neste sentido, este levantamento procura identificar, inicialmente, como se apresentam os estudos deste tema na última década e se abarcam essa variedade. 


\section{REVISTA PAUTA GERAL}

\section{ESTUDOS EM JORNALISMO}

10.5212/RevistaPautaGeral.v.6.i2.00010

\section{Assédio moral e sexual e mercado de trabalho}

Pontualmente, o assédio moral é caracterizado por ataques repetitivos e cotidianos, quando o agressor trata o/a trabalhador(a) com rigor excessivo, gritos, humilhações, desprezo e ameaça o emprego da vítima, sendo que esse tipo de prática pode estar relacionado a questões de gênero e/ou raça. Ele pode ocorrer de forma vertical, quando o agressor ocupa um cargo superior à vítima; ou horizontal, quando é praticado pelos próprios colegas de trabalho. No Brasil, não há uma legislação unificada tratando do tema, embora a Constituição Federal trate da dignidade da pessoa humana (SOARES; DUARTE, 2014).

Já o assédio sexual é uma espécie agravada do moral. Tem como característica o constrangimento por palavras, gestos ou atos com o objetivo de obter vantagem sexual. Assim, como no moral, pode se apresentar de forma vertical ou horizontal, porém ainda não há leis que punam agressores com hierarquia igual ou de patente inferior (NUNES; REGO, 2011). Em 2001, essa prática passou a ser considerada crime, com pena prevista de detenção de um a dois anos. Além disso, a legislação permite a demissão por justa causa, caso um funcionário pratique esse crime ${ }^{5}$.

A pesquisa "Assédio sexual entre as mulheres. Instituto de Pesquisa Datafolha, Opinião Pública. Brasil”, realizada pelo DataFolha (2017), apontou que $42 \%$ das brasileiras com 16 anos ou mais declararam já terem sido vítimas de assédio sexual, sendo que é mais comum o relato de assédio entre as mais escolarizadas (57\%), o que pode estar relacionado com a percepção do que seria este crime. No ambiente de trabalho, $15 \%$ das brasileiras contaram já terem sido assediadas fisicamente $(2 \%)$ e verbalmente $(11 \%)$.

Já no Jornalismo, de acordo com a pesquisa "Gênero e Número: Mulheres no jornalismo Brasileiro", da Abraji, de 2017, realizada com profissionais do Rio de Janeiro, de Porto Alegre, de Brasília e de São Paulo, mostrou que 70,2\% das mulheres entrevistadas já presenciaram ou souberam de colegas que foram assediadas durante o exercício da profissão. Além disso, 86,4\% admitiram já ter passado por pelo menos uma situação de discriminação de gênero no trabalho e quase todas as jornalistas $(92,3 \%)$ disseram já ter ouvido piadas machistas ridicularizando mulheres ou banalizando situações de violência, $70,4 \%$ afirmaram já ter recebidos cantadas que as deixaram desconfortáveis, e 10,7\% admitem já terem recebido proposta de favores sexuais em

${ }^{5}$ Código Penal, art. 216-A.

Revista Pauta Geral-Estudos em Jornalismo, Ponta Grossa, v. 6, n. 2, p. 153-170, Jul/Dez, 2019 


\section{REVISTA PAUTA GERAL}

\section{ESTUDOS EM JORNALISMO}

10.5212/RevistaPautaGeral.v.6.i2.00010

troca de algum benefício profissional ou material. Todas essas situações durante o exercício da profissão. Apesar da recorrência apontada pela pesquisa, apenas $15 \%$ das mulheres contaram que já denunciaram situações de assédio moral ou sexual. Fator que pode estar relacionado a outro problema: conforme o levantamento, as empresas não têm canal de denúncia e quando tem não são considerados eficazes (GÊNERO E NÚMERO: MULHERES NO JORNALISMO BRASILEIRO, 2017).

Outro levantamento realizado com as jornalistas de Curitiba (PR) revelou dados bem parecidos, mas traz outros apontamentos, como por exemplo, de que o assédio moral vertical, praticado por pessoas de cargos superiores é o mais percebido. Sobre o assédio cometido por fontes de entrevistas, todas as jornalistas disseram já terem sido vítimas. Em relação ao assédio sexual, 40\% das entrevistadas afirmaram que o assédio partiu de um homem, enquanto $6 \%$ de mulher. Segundo as jornalistas ouvidas, a maior parte $(66 \%)$ dos assédios sexuais é cometida por superiores e por fontes (PORTELA, 2018).

Outra pesquisa realizada entre os anos de 2011 e 2015, em São Paulo, com 21 entrevistadas, mostrou que alguns casos as vítimas não usam o termo assédio, mas relatam situações que podem ser assim consideradas. Entre os episódios, está a cobrança excessivano trabalho e histórias de mulheres que saíam da redação chorando ao ouvirem gritos ou ao sofrerem perseguições. Embora não fosse o objeto do levantamento, o assédio sexual acabou aparecendo em três relatos. Em um deles, a assediada foi demitida por não aceitar ter relações sexuais com o assediador. O estudo apontou que o assédio moral e sexual é uma questão organizacional e que as relações são naturalizadas a tal ponto que se impede a reação da vítima (REIMBERG, 2015).

De um modo geral, o que esses dados apontam é que, embora o mercado seja ocupado na maior parte por mulheres, no exercício da profissão de jornalista é comum a violência de gênero (PORTELA, 2018). Revelam ainda que as desigualdades, as relações, o processo de ascensão e a divisão de trabalho são influenciados por questões de gênero (GÊNERO E NÚMERO: MULHERES NO JORNALISMO BRASILEIRO, 2017).

\section{Estado da Arte como metodologia}

O Estado da Arte é uma metodologia que se baseia no mapeamento de pesquisas e estudos sobre um tema, método ou outra categoria que possa contribuir para enxergar um campo de estudo mais pontualmente. Por meio de tal estudo é possível identificar 


\section{REVISTA PAUTA GERAL}

\section{ESTUDOS EM JORNALISMO}

10.5212/RevistaPautaGeral.v.6.i2.00010

como o assunto tem sido tratado, as lacunas visíveis, bem como os apontamentos e desenvolvimento das produções acadêmicas, contribuindo para o campo teórico. Serve também para analisar, categorizar e indicar os enfoques e perspectivas do conhecimento já produzido por outros autores. Assim, pode colaborar para organização, definição de campo e quaisquer outros subsídios possíveis de uma nova pesquisa (ROMANOWSKI; ENS, 2006).

De caráter bibliográfico, essa metodologia tenta descobrir investigações já realizadas e, a partir de então, traçar um caminho (FERREIRA, 2002). Alguns autores, como por exemplo, Vosgerau e Romanowski (2014), classificam essa metodologia como "Estudos de Revisão", que são aqueles que esclarecem e resumem as principais pesquisas, oferecendo um panorama das obras existentes. São levantamentos que mostram a integração, configurações emergentes, perspectivas e recorrências, bem como as lacunas e contradições das investigações científicas.

Neste artigo, optou-se pelo Estado da Arte para levantar como o assédio sexual e moral contra jornalistas têm sido tratados nas pesquisas brasileiras atuais. Para isso, em um primeiro momento, buscaram-se publicações de teses e dissertações localizadas no Banco de Dados da Coordenação de Aperfeiçoamento de Pessoal de Nível Superior (Capes). Para ampliar os resultados foram incluídos os anais da Associação Brasileira de Pesquisadores em Jornalismo (SBPJOR) e nas revistas Famecos, Galaxia e Estudos Feministas. Embora haja outros periódicos reconhecidos e com qualificação igual ou superior, esse recorte pretende ser um olhar inicial sobre o modo como a pesquisa tem sido conduzida na área.

Em todas as plataformas selecionadas foram utilizadas como filtros as palavraschaves: assédio + jornalistas + mulheres. Essa escolha se justifica por serem termos que sintetizam o tema central que se pretendia investigar neste levantamento. $O$ recorte temporal inclui os últimos 10 anos. O estudo recortou inicialmente as pesquisas relacionadas a mulheres e/ou gênero na Comunicação, identificadas por meio do título, partindo do pressuposto de que os títulos mostram a informação principal e as características do conteúdo do trabalho (FERREIRA, 2002).

Os artigos localizados foram catalogados da seguinte forma: título, ano, metodologia, objeto de estudo, a região geográfica e área da Comunicação em que a pesquisa foi realizada. A área recebeu a classificação de Cinema, Jornalismo, Publicidade e Propaganda, Relações Públicas e outros - destinada aquelas que não se enquadraram 


\section{REVISTA PAUTA GERAL}

\section{ESTUDOS EM JORNALISMO}

10.5212/RevistaPautaGeral.v.6.i2.00010

em nenhuma das categorias anteriores. O intuito foi ter um panorama sobre como a academia desenvolve estudos relacionados ao assédio sexual e moral contra as jornalistas.

\section{Mapeamento das pesquisas}

Este estudo identificou no total, 784 publicações selecionadas pelas palavraschave citadas. Porém, as que tratavam de gênero ou envolviam mulheres foram apenas 142. Quando se trata das que abordam diretamente o assédio, o número é ainda menor: apenas duas pesquisas, sendo uma na Capes e outra no SBPJOR. As pesquisas, na maior parte, são análises sobre mulheres no jornalismo, enquanto personagens de diversas produções, como filmes, novelas ou fontes dos jornais. Porém, poucas abordam as jornalistas, conforme veremos mais detalhadamente a seguir.

\subsection{Teses e dissertações}

Com as palavras assédio + jornalistas + mulheres foram encontrados 708 estudos publicados nos últimos 10 anos na área de Comunicação e Informação na plataforma da Capes, porém, a maior parte não estava relacionada com o tema assédio. Quando recortamos, por meio dos títulos, as pesquisas relacionadas a mulheres e/ou gênero na Comunicação, o número caiu para 141. Mais pontualmente sobre assédio foi encontrado apenas um trabalho, embora outros quatro acabem por tangenciar 0 assunto no desenvolvimento da pesquisa.

De um modo geral, os estudos sobre Gênero e Comunicação se concentram nas áreas onde há mais programas - Região Sudeste (76 publicações), seguida pelo seguida pelo Centro-Oeste e Sul, que ficaram empatadas (22 publicações), e na sequência Nordeste (8) e Norte (3). Quanto à área que mais se dedicam ao tema, o Jornalismo concentra o maior número de estudos, com 48 pesquisas; seguido do Cinema, com 24, e da Publicidade com 11. Nenhum estudo foi encontrado na área das Relações Públicas. $O$ montante de 52 pesquisas categorizadas como outrasincluem estudos voltados telenovela, fotografias, música, quadrinhos etc.

A predominância do jornalismo como objeto de investigação apontada neste levantamento, reforça a tendência histórica de destaque da área. Mais de um quinto das teses e dissertações brasileiras de Comunicação tematizam o Jornalismo desde os anos 1970 (PONTES, ALMEIDA, 2017). 


\section{REVISTA PAUTA GERAL}

\section{ESTUDOS EM JORNALISMO}

10.5212/RevistaPautaGeral.v.6.i2.00010

Outro apontamento encontrado é sobre as metodologias usadas nas pesquisas. Parte considerável dos estudos adota a Análise do Discurso, com 23 ocorrências; a Análise de Conteúdo, com 21 casos; ou combina esta com outras metodologias, 33 (híbridas). Entre a combinação mais comum está a Análise de Discurso e de Conteúdo com entrevistas. Há metodologias menos recorrentes, como pesquisas que utilizaram somente entrevista (3), análise fílmica (8), bibliográfica (7), etnografia (6), entre outras.

Este estudo mostrou ainda que a pesquisa relacionada a Gênero no Jornalismo tem crescido nos últimos anos, na Capes. As pesquisas que se encaixaram nos critérios estabelecidos aumentaram ao longo do tempo. Embora o recorte seja a partir de 2009, o ano de 2013 foi o primeiro que pontuou com 17 estudos publicados. Em 2014 foram 29; em 2015, 21; seguidos de 2016, com 22; 2017, com 21 e 2018, com 31 ocorrências.

Embora o crescimento dos estudos relacionados ao gênero e/ou mulher no jornalismo seja animador, apenas uma pesquisa foi publicada na plataforma Capes nos últimos 10 anos relacionada diretamente ao assédio sexual e moral contra jornalistas. Trata-se de uma dissertação, produzida na Universidade Federal de Goiás, por Ana Maria Moraes, com o título "Feminização do Jornalismo e desigualdades de gênero no exercício da profissão em Goiânia". A partir das narrativas das jornalistas, coletadas por meio de entrevistas, a autora analisa questões como condições de trabalho, relações das jornalistas com a chefia, entre outros. Entre as conclusões, Moraes (2018) aponta que a mulher, em uma posição de chefia, quando adota posturas semelhantes a dos homens recebe diversos rótulos, como de durona ou estressada, além de terem que constantemente provar sua competência. A respeito das percepções das desigualdades de gênero, elas vão desde a distribuição de pautas até situações de assédio moral.

Outro estudo que, ainda que não seja o tema central, aborda a temática foi "A (in)visibilidade das mulheres em programas esportivos de TV: um estudo de casos no Brasil e em Portugal". A tese de Noemi Corrêa Bueno, apresentada à Universidade Estadual Paulista Júlio de Mesquita Filho, em 2018, aborda o tema nos apontamentos como uma das dificuldades a serem superadas na área. Ela expõe os principais casos de assédio relatados pelas profissionais durante a pesquisa, entre os mais comuns estão comentários sobre o corpo, aparência ou perguntas sobre a vida amorosa. As jornalistas disseram ainda adotar determinadas posturas para evitar que sejam assediadas, como não se relacionar com jogadores ou evitar alguns tipos de roupas. 


\section{REVISTA PAUTA GERAL}

\section{ESTUDOS EM JORNALISMO}

10.5212/RevistaPautaGeral.v.6.i2.00010

A dissertação "Crítica, moral e espetáculo: o caso do feminismo digital", da Universidade Federal do Rio de Janeiro, de 2016, também aborda o tema. Embora o foco de estudo sejam os discursos de inclinação política de Direta e Esquerda. Ainda assim, a pesquisa acaba por contribuir para este levantamento, uma vez que analisa as manifestações contra o assédio "Eu não mereço ser estuprada", "O corpo é meu" e "Primeiro Assédio". A autora, Beatriz Moreira da Gama de Malcher, mostra que há um esvaziamento do sentido social e que o discurso de empoderamento se move sobre as bases da espetacularização.

Apesar de não ser o tema central desse levantamento, cabe destacar que duas pesquisas mencionaram a questão do gênero na divisão sexual de trabalho, que tem relação direta com o assédio. Uma delas é a tese da Universidade de Brasília "Parresia e hermenêutica de profundidade nas trilhas de Hermes: raça e gênero em formas simbólicas sobre o jornalismo como profissão no Brasil”, de 2016. Nela, a autora Isabel Cristina Clavelin da Rosa, trata de questões relacionadas à dimensão de raça e de gênero no jornalismo como profissão no Brasil, apontando as diferenças na trajetória profissional. A outra foi apresentada à Universidade Metodista de São Paulo e se intitula "Mulheres no fotojornalismo: Uma análise cultural da relação entre identidades de gênero e a prática do fotojornalismo na contemporaneidade", de Nathália Cunha da Silva, de 2017. A dissertação tem o objetivo de compreender como as mulheres fotojornalistas atuam e percebem suas práticas na profissão. A autora aponta que as mulheres enfrentam barreiras por questões relacionadas a gênero, como a divisão do papel social. 


\section{REVISTA PAUTA GERAL}

\section{ESTUDOS EM JORNALISMO}

10.5212/RevistaPautaGeral.v.6.i2.00010

\section{Figura 1 - Pesquisas publicadas na plataforma da Capes}

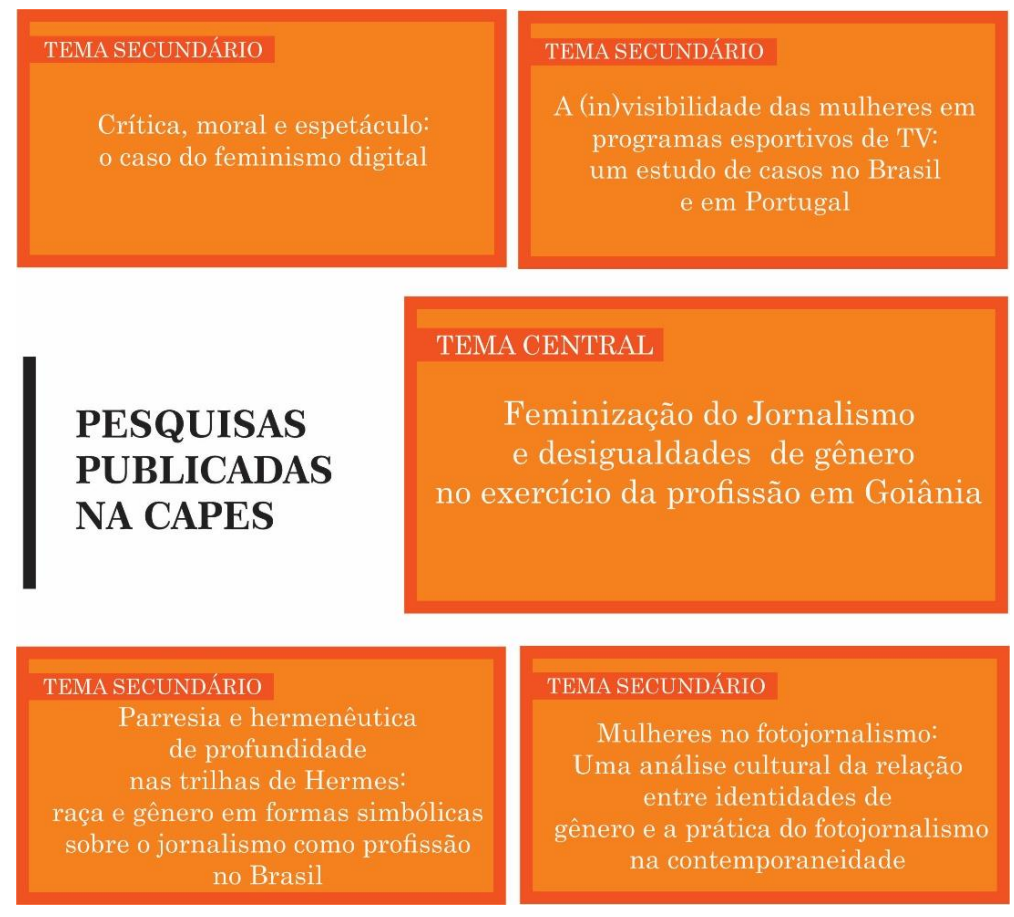

Fonte: Produzida pelas autoras.

O assédio apareceu ainda em outras 14 pesquisas, porém apenas citado, na maior parte das vezes, como pauta do movimento feminista, principalmente mencionando as campanhas nas redes sociais a partir de 2013. Isso mostra que o assédio contra as jornalistas ainda tem sido pouco abordado como tema central de pesquisas nos programas de pós-graduação no Brasil.

\subsection{Anais do evento SBPJOR}

Nos anais da SBJOR, os artigos estavam disponíveis online a partir de 2016, sendo que em 2018 foi publicado um sobre a temática investigada neste artigo. Nos demais anos, nenhuma pesquisa com essa temática foi encontrada no acervo. Com o título "Mudanças na rotina profissional de mulheres jornalistas devido ao assédio sexual, verbal e moral", Letícia Kutzke e Tatiane Gonsale relatam um estudo baseado em entrevista com 181 mulheres jornalistas para compreender questões sobre a forma que o assédio acontece.

Entre os apontamentos das pesquisadoras estão as consequências do assédio, como parada cardíaca, crise de stress e ansiedade, mudança de comportamento (as 


\section{REVISTA PAUTA GERAL}

\section{ESTUDOS EM JORNALISMO}

10.5212/RevistaPautaGeral.v.6.i2.00010

vítimas passam a evitar os assediadores e até repensar as roupas), interferência na rotina de trabalho e demissão. Este trabalho, embora seja o único encontrado, é importante porque, diferentemente dos outros mapeados nesse Estado da Arte evidenciam mais as práticas de assédio epoucos se debruçam sobre as consequências física e psicológica para as jornalistas.

\subsection{Periódicos qualificados}

Nos periódicos foram encontradas 75 publicações, porém nenhum aborda 0 assédio contra mulheres jornalistas. Essa ausência nas revistas mostra que a necessidade de estudar se dá também em outras instâncias e não apenasna pósgraduação.

\subsubsection{Famecos}

$\mathrm{Na}$ revista Famecos foram encontrados 53 artigos sobre gênero, e recortando as pesquisas com mulher e jornalismo no título esse número caiu para 10 estudos. Porém, nenhum abordou a questão do assédio, mesmo que indiretamente, realçando, outra vez, a escassez de pesquisas sobre o tema.

Entre os que de algum modo podem dialogar com 0 assunto está 0 artigo "Jornalistas expostos e vulneráveis: ataques digitais como modalidade de risco profissional", publicado em 2018, de autoria de Rogério Christofoletti e Ricardo José Torres, da Universidade Federal de Santa Catarina. Embora trate de violência contra jornalistas em mídias digitais o trabalho não tem foco nas questões de gênero e não cita o assédio quando analisa relatórios sobre agressões a jornalistas e ataques à liberdade de imprensa de nove organizações não-governamentais.

A primeira pesquisa mapeada na Famecos é de 2008. Nos anos de 2010 e entre 2012 e 2015 a revista não publicou nada relacionada a gênero. Somente a partir de 2016 houve a publicação continua de pelo menos um artigo, o que infere que o interesse por esse assunto é recente.

\subsubsection{Galáxia}

$\mathrm{Na}$ Galáxia, foram identificados, a partir dos filtros estabelecidos nesse Estado da Arte, 22 artigos. Na segunda seleção, que leva em conta a presença da mulher e da comunicação no título, o número rastreou seis artigos e destes nenhum teve como foco o 


\section{REVISTA PAUTA GERAL}

\section{ESTUDOS EM JORNALISMO}

10.5212/RevistaPautaGeral.v.6.i2.00010

assédio. Assim como na Famecos, a Galáxia não apresenta nenhum trabalho em que o tema assédio sexual e moral apareça de forma direta ou indireta nos últimos 10 anos.

\subsubsection{Estudos Feministas}

Na revista Estudos Feministas a busca encontrou dois artigos que, embora não sejam na área de Comunicação, acabam por contribuir para a discussão sobre o assédio contra mulheres. O primeiro, de Ludmila Ribeiro, da Universidade Federal de Minas Gerais, recebeu o título de "Polícia Militar é lugar de mulher?" (2018) e trata das percepções do lugar da mulher na Corporação. Por meio de um estudo quantitativo, a pesquisadora aponta o assédio sexual e moral como algo presente na rotina dos profissionais e, às vezes, até valorizado, já que há uma visão de que o assédio prepara melhor os policiais.

Esse resultado aponta para a necessidade de estudos relacionados a mulheres na Comunicação, em especial sobre o assédio, já que uma das principais revistas sobre gênero do Brasil não possui, até o presente momento, nenhuma publicação sobre o assunto.

\section{Discussão dos resultados}

O primeiro estudo com as palavras chaves assédio + jornalistas + mulheres apareceu em 2009, com uma publicação na Galáxia. Até 2012 - anos em que houve apenas dois estudos - assinalando que a produção é bem escassa em todas as plataformas analisadas. Nas teses e dissertações, somente em 2013 é que o tema aparece. É quando a produção acadêmica começa a ter uma regularidade e, apesar de escassa, é mais expressiva. Para se ter uma idéia, em 2013 foram 17 publicações; já em 2018, encontrou-se 36 pesquisas. O fato das pesquisas aparecerem somente nesta investigação mais significativamente a partir de 2013, pode estar relacionado ao período em que as pautas feministas latino-americanas ganharam mais visibilidade. Como já citado anteriormente, foi nesse ano que surgiram campanhas como "Chega de FiuFiu". Até do ponto de vista jurídico, o debate é recente. Somente em 2018 foi sancionada a lei que considera a importunação sexual um crime.

Em relação à localização geográfica, as pesquisas são predominantes no Sul, Sudeste e Centro-Oeste, sendo que Norte e Nordeste chegam a nem aparecer em alguns periódicos, como na Famecos. Essa desigualdade na produção de pesquisas pode ser 


\section{REVISTA PAUTA GERAL}

\section{ESTUDOS EM JORNALISMO}

10.5212/RevistaPautaGeral.v.6.i2.00010

associada da distribuição de recursos científicos. No Sul e Sudeste - regiões com maiores números - há mais universidades e institutos consolidados (SIDONE; HADDAD; MENACHALCO, 2016). Por outro lado, apesar da disparidade de locais onde o tema aparece e é perceptível que nos últimos anos o assunto tem sido debatido em todas as regiões do país, o que ratifica sua importância.

A respeito da área da Comunicação, a pesquisa em jornalismo lidera e reforça a tendência histórica de destaque para o jornalismo como objeto de investigação. Cabe destacar que elas são maioria, se somada todas as produções catalogadas neste levantamento e também entre as teses e dissertações. No entanto, nas revistas científicas o mais comum são trabalhos na área do cinema, na maioria dos casos são análises dos filmes. Quanto a metodologia, a maior parte dos estudos são híbridos. Se considerarmos que entre as combinações é comum a presença de Análise do Discurso ou do Conteúdo, bem como Entrevistas, percebemos que estas são metodologias bem presentes nas pesquisas mapeadas. Para Moura e Lopes (2016), a combinação de métodos deve ser usada para dar conta de objetos cada vez mais complexos. A maior parte das pesquisas é voltada aos produtos midiáticos, daí a grande incidência das análises discursivas e de conteúdos como metodologia. Por outro lado, poucas focam no processo de produção ou em quem produz. Logo, há poucas incidências de produção acadêmica sobre assédio sexual e moral na rotina de trabalho das jornalistas, seja como tema central ou secundário.

As pesquisas que tratam do assédio moral e sexual no jornalismo ainda são bastante escassas, apesar do aumento de estudos sobre gênero. Porém, as que foram publicadas trazem apontamentos importantes, entre eles que o assédio é uma prática comum nas redações, que há diferenças na trajetória profissional entre homens e mulheres, na divisão sexual de trabalho e na reprodução de estereótipos. Isso mostra que o assédio é uma das dificuldades a serem superadas na área e aponta para a necessidade de evidenciar o tema.

Vale ressaltar que nas pesquisas já realizadas não incluem jornalistas professoras ou pesquisadoras da área, sendo essa uma possibilidade de ampliação nas análises. Cabe pontuar, ainda, que poucos estudos são direcionados ao jornalista ou ao processo de produção da notícia, o que é uma falha grave tendo em vista a função social do jornalismo e consequentemente de quem o produz. 


\section{REVISTA PAUTA GERAL}

\section{ESTUDOS EM JORNALISMO}

10.5212/RevistaPautaGeral.v.6.i2.00010

\section{Considerações finais}

Embora haja poucas pesquisas relacionadas ao assédio moral e sexual contra jornalistas, todos os estudos mapeados nesse levantamento apontam que essa é uma prática recorrente nas redações em várias partes do Brasil, o que mostra que o tema é real e precisa ser investigado. O silenciamento sobre essa temática precisa ser rompido, inclusive na academia, já que o assédio tem sido parte da rotina das mulheres jornalistas.

O estudo mostra que o tema, embora recorrente na prática da profissão, tem recebido pouco espaço como pesquisa central entre os estudiosos, inclusive de gênero. Esse resultado preocupa porque entender o assunto é importante, uma vez que muito se trata de como o jornalismo mudou, na sua prática, no seu consumo, nas suas rotinas etc, mas a questão que fica é: o quanto essas mudanças refletem nas relações sociais e de gênero na redação?

Discutir o assédio no jornalismo é mais do que como se estruturam as carreiras e é fundamental porque isso se reflete em vários campos sociais, como no comportamento, discursos e até mesmo nos corpos - como mostrou as pesquisas elencadas neste Estado da Arte. Pesquisar sobre esse tema é uma forma de mostrar que o problema existe, que precisa ser combatido e, consequentemente, melhorar as condições de trabalho das mulheres.

Mais pontualmente, este estudo ratifica o papel importante do Estado da Arte como uma metodologia que permite enxergar de maneira ampla uma temática de pesquisa, apontando saturações e lacunas, bem como inspirando e apontando caminhos.

Cabe mencionar ainda que este levantamento não tenha a pretensão de ser definitivo, uma vez o recorte é pequeno diante da quantidade de eventos e periódicos igualmente reconhecidos e qualificados. Ainda assim, permite enxergar preliminarmente como o tema tem sido debatido e possíveis espaços para aprofundamento nas investigações futuras.

\section{Referências}

ABRAJI; GÊNERO E NÚMERO. Mulheres no jornalismo Brasileiro, 2017. [Relatório técnico]. Disponível em: <http://www.mulheresnojornalismo.org.br/ 12901_GN_relatorioV4.pdf>. Acesso em 23 de junho de 2019.

ALMEIDA, Rodrigo de Souza. Doenças Psíquicas decorrente do assédio moral. Trabalho de Conclusão de Curso. Curso de Direito, Universidade Federal de Juiz de Fora, 2016. Disponível em: 


\section{REVISTA PAUTA GERAL}

\section{ESTUDOS EM JORNALISMO}

10.5212/RevistaPautaGeral.v.6.i2.00010

https://repositorio.ufjf.br/jspui/bitstream/ufjf/3914/1/rodrigodesouzaalmeida.pdf. Acesso de 2 de setembro de 2019.

ANDRADE, Cristiane Batista; ASSIS, Simone Gonçalves. Assédio moral no trabalho, gênero, raça e poder: revisão de literatura. Revista Brasileira de Saúde Ocupacional. 2018. Disponível em: http://dx.doi.org/10.1590/2317-6369000012917RBSO. Acesso em 20 de junho de 2019.

ASSÉDIO sexual entre as mulheres. Instituto de Pesquisa Datafolha, Opinião Pública. Brasil, 29 e 30/11/2017. Disponível em:

http://media.folha.uol.com.br/datafolha/2018/01/11/bfed1c72cc0eff5f76027203648546c5bb e9923c.pdf. Acesso em 23 de junho de 2019.

BRASIL.Lei № 13.718, de 24 de Setembro de 2018. Diário Oficial da União - Seção 1 25/9/2018, Página 2.

BUTLER, Judith. Problemas de Gênero. Feminismo e Subversão da Identidade. Rio de Janeiro: Civilização Brasileira, 2003.

CASADEI, Elisa Bachega. A inserção das mulheres no jornalismo e a imprensa alternativa: primeiras experiências do final do século XIX. RevistaALTERJOR. Grupo de Estudos Alterjor: Jornalismo Popular e Alternativo (ECA-USP) Ano 02- Volume 01 Edição 03 - Janeiro-Junho de 2011. Disponível em:

http://www.usp.br/alterior/ojs/index.php/alterjor/article/viewArticle/aj3-d3. Acesso em 26 de junho de 2019.

COLETIVO de Mulheres Jornalistas do DF lança pesquisa sobre assédio sexual no trabalho.Sindicato dos Jornalistas Profissionais do Distrito Federal, 2017. Disponível em: https://www.sjpdf.org.br/noticias-teste/3821-coletivo-de-mulheres-jornalistas-do-dflanca-pesquisa-sobre-assedio-sexual-no-trabalho. Acesso em 30 de setembro de 2019.

DUARTE, Bento Herculano; SOARES, Fernanda de Carvalho. O assédio moral no ordenamento jurídico brasileiro. R. Fórum Trabalhista - RFT. Belo Horizonte, ano 3, n. 11, p. 21-47, mar./abr. 2014. Disponível em:http://www.editoraforum.com.br/wpcontent/uploads/2014/06/O-assedio-moral-no-ordenamento-juridico-brasileiro.pdf. Acesso em 23 de junho de 2019.

DUARTE, Constância Lima. "Feminismo e Literatura no Brasil". Estudos Avançados, volume 17, número 49, São Paulo, 2003. Disponível em: http://dx.doi.org/10.1590/S010340142003000300010 . Acesso em 23 de junho de 2019.

FACEBOOK completa 15 anos com 2,3 bilhões de usuários. G1, 2019. Disponível em: https://g1.globo.com/economia/tecnologia/noticia/2019/02/04/facebook-completa-15-anoscom-23-bilhoes-de-usuarios.ghtml. Acesso em 02.05.2019

FERREIRA, Norma Sandra de Almeida. As pesquisas denominadas Estado da Arte.Educação \& Sociedade, ano XXIII, no 79, Agosto/2002. Disponível em: http://www.scielo.br/pdf/es/v23n79/10857.pdf. Acesso em 23 de junho de 2019. 


\section{REVISTA PAUTA GERAL}

\section{ESTUDOS EM JORNALISMO}

10.5212/RevistaPautaGeral.v.6.i2.00010

HIGA, Flávio da Costa. Assédio sexual no trabalho e discriminação de gênero: duas faces da mesma moeda?.Revista direito GV. São Paulo. v. 12 n. 2. Mai-ago, 2016. Disponível em: http://dx.doi.org/10.1590/2317-6172201620. Acesso em 20 de junho de 2019.

LOURO, Guacira Lopes. Gênero, Sexualidade e Educação. Uma perspectiva pósestruturalista. Petrópolis, RJ. Vozes, 1997.

LOPES, Maria ImmacolataVassallo de; MOURA, Cláudia Peixoto de. Pesquisa em comunicação: metodologias e práticas acadêmicas. Porto Alegre. EDIPUCRS, 2016.

MASSUCHIN,Michele Goulart; LIMA, Daniele Silva. Quem vai dar visibilidade para a nossa realidade? Diferenças de gênero nas rotinas de produção das empresas de comunicação em Imperatriz (MA). In: BERTOTTI, Bárbara Mendonça; VIANA, Ana Cristina Aguilar; KREUZ, Letícia Regina Camargo; CALEFFI, Renata. Gênero e resistência, volume 1: memórias do II encontro de pesquisa por/de/sobre mulheres. Porto Alegre, RS: Editora Fi, 2019

NO BRASIL, mais de $70 \%$ das jornalistas já sofreram assédio durante o trabalho. Portal Imprensa, 2019. Disponível em:http://portalimprensa.com.br/noticias/ultimas noticias/81757/no+brasil+mais+de+70+d as+jornalistas+ja+sofreram+assedio+durante+o+trabalho. Acesso em 23 de setembro de 2019.

NUNES, Maria Terezinha; REGO, Andrea de Castro Souza. Assédio Moral e Sexual. Programa Pró-Equidade de Gênero e Raça. Senado Federal. Disponível em:http://www2.senado.leg.br/bdst/handle/id/509899. Acesso em 23 de junho de 2019.

PORTELA, Monique Ryba. Percepção do assédio moral e sexual contra mulheres jornalistas em Curitiba. Trabalho de Conclusão de Curso. Curso de Comunicação Social. Universidade Federal do Paraná, 2018. Disponível em: https://acervodigital.ufpr.br/handle/1884/56614. Acesso em 11 de junho de 2019.

PROBST, Elisiana Renata. Evolução da Mulher no mercado de trabalho. 2007 Dissertações (Pós Graduação em Gestão Estratégica de Recursos humanos) - Instituto Catarinense de Pós Graduação, Santa Catarina, 2007. Disponível em:

http://www.posuniasselvi.com.br/artigos/rev02-05.pdf. Acesso em 20 de junho de 2019.

REIMBERG, Cristiane Oliveira. Quando o trabalho do jornalista é cenário para o assédio moral. Intercom - Sociedade Brasileira de Estudos Interdisciplinares da Comunicação XXXVIII Congresso Brasileiro de Ciências da Comunicação - Rio de Janeiro, RJ - 4 a 7/9/2015. Disponível em: http://portalintercom.org.br/anais/nacional2015/resumos/R101980-1.pdf. Acesso em 10 de julho de 2019.

ROMANOWSKI, Joana Paulin; ENS, Romilda Teodora. As pesquisas denominadas do tipo "Estado da Arte" em Educação. Revista Diálogo Educacional, Curitiba, v. 6, n.19, p.3750, set./dez. 2006. Disponível em: http://redalyc.org/articulo.oa?id=189116275004. Acesso em 23 de junho de 2019. 


\section{REVISTA PAUTA GERAL}

ESTUDOS EM JORNALISMO

10.5212/RevistaPautaGeral.v.6.i2.00010

SCOTT, Judith. Gênero: uma categoria útil de análise histórica. Educação \& Realidade. Porto Alegre, vol. 20, no 2, jul./dez. 1995, pp. 71-99.

SIDONE, Otávio José Guerci; HADDAD, Eduardo Amaral; MENA-CHALCO, Jesús Pascual. A ciência nas regiões brasileiras: evolução da produção e das redes de colaboração científica TransInformação, Campinas, 28(1):15-31, jan./abr., 2016. Disponível em: http://www.scielo.br/pdf/tinf/v28n1/0103-3786-tinf-28-01-00015.pdf. Acesso em 01 de julho de 2019.

UNESCO fará estudo para combater o assédio online a jornalistas do sexo feminino. Portal Imprensa, 2019. Disponível em:

http://portalimprensa.com.br/noticias/ultimas noticias/81672/unesco+fara+estudo+para+co mbater+o+assedio+online+a+jornalistas+do+sexo+feminino. Acesso em 23 de setembro de 2019.

UFSC; FENAJ. Quem é o jornalista brasileiro? Perfil da profissão no Brasil, 2012. Disponível em https://fenaj.org.br/wp-content/uploads/2016/01/pesquisa-perfil-jornalistabrasileiro.pdf. Acesso em 23 de junho de 2019.

VOSGERAU, Dilmeire Sant'Anna Ramos; ROMANOWSKI, Joana Paulin. Estudos de revisão: implicações conceituais e metodológicas. Revista Diálogo Educacional, Curitiba, v. 14, n. 41, p. 165-189, jan./abr. 2014. Disponível em https://periodicos.pucpr.br/index.php/dialogoeducacional/article/view/2317/2233. Acesso em 04 de julho de 2019.

Recebido em: 05/10/2019

Aprovado em: 30/11/2019 